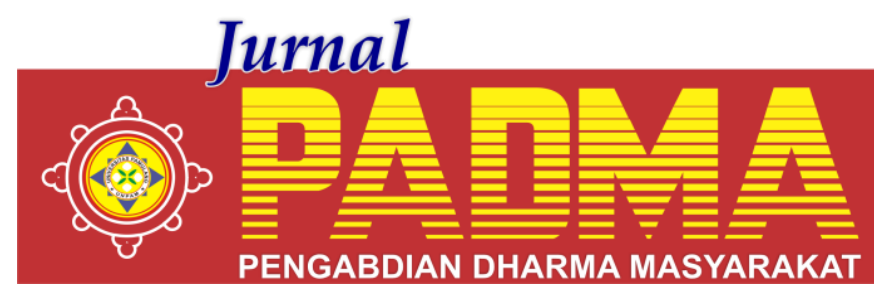

VOLUME I, NOMOR 3, JULI 2021

\title{
PELATIHAN PENINGKATAN KUALITAS DESAIN KEMASAN PRODUK UKM DI DESA KEDAUNG
}

\author{
${ }^{1 *}$ Septi Rostika Anjani, ${ }^{2}$ Anggi Ayu Wandini, ${ }^{3}$ Dimas Aziz Malpaci, 4 Muh. Dwi Andri Putra, \\ ${ }^{5}$ Muh. Tri Andre Putra, ${ }^{6}$ Muhammad Faisal Alwi \\ Universitas Pamulang, Tangerang Selatan, Banten, Indonesia \\ *dosen01699@unpam.ac.id
}

\begin{abstract}
Abstrak
Usaha Kecil dan Menengah (UKM) merupakan tulang punggung perekonomian nasional. UKM merupakan hal yang sangat penting dalam menghadapi era industri 4.0. Terlebih, Sektor ini mampu menggerakkan perekonomian masyarakat dan menyerap tenaga kerja dalam jumlah besar. Namun, kerap kali ditemukan kemasan (Packaging) Produk UKM belum bisa bersaing dengan produk pabrikan. Salah satu solusinya adalah dengan memperhatikan desain kemasan produk UKM. Dengan kegiatan ini akan diberikan pembinaan dan pelatihan kepada 10 pemilik Usaha Kecil dan Menengah di Desa Kedaung untuk memperbaiki kemasan produk UKM yang diharapkan dapat meningkatkan pemasaran, segmen pasarnya semakin bertambah, dan omset pemasaran semakin meningkat. Sehingga Produk-produk UKM dapat mampu besaing dengan produk di Industri besar.
\end{abstract}

Kata Kunci : Kemasan, Produk, UKM, Pemasaran

\section{Abstract}

Small and Medium Enterprises (SMEs) are the backbone of the national economy. SMEs are very important in the face of the industrial era 4.0. Moreover, the sector is able to drive the economy of the community and absorb a large amount of labor. However, often found packaging (Packaging) SME products can not compete with the manufacturer's products. One solution is to pay attention to the packaging design of SME products. With this activity will be given coaching and training to 10 small and medium business owners in Kedaung Village to improve the packaging of SME products that are expected to increase marketing, the market segment is increasing, and marketing turnover is increasing. So that SME products can be able to be compared with products in large industries.

Keywords : Packaging, Products, SMEs, Marketing

\section{PENDAHULUAN}

Usaha kecil dan menengah (UKM) berperan penting dalam mendorong pertumbuhan ekonomi Indonesia. Dukungan sektor UKM memberikan peluang kesempatan kerja bagi yang tidak tertampung di dunia kerja pemerintahan maupun perusahaan-perusahaan menengah dan besar.

Kerasnya persaingan pasar UKM ternyata tak menjamin produk berkualitas bagus selalu ramai diserbu pembeli. Pasalnya, sekarang ini konsumen tidak hanya melihat kualitas produknya saja, tapi cenderung lebih tertarik dengan tampilan desain kemasan yang membungkusnya. Pelanggan akan jatuh cinta pada produk UKM jika tampilannya cantik danmenarik. Sayangnya, sampai hari ini perkara kemasan produk masih sering disepelekan pelaku UKM. Pertama karena masih keberatan dengan biaya produksi kemasan, kedua karena UKM belum mengerti dimana mereka harus pesan kemasan produk.

Salah satu upaya yang dapat dilakukan untuk pemberdayaan UKM adalah pelatihan desain kemasan produk. Banyak produk sejenis di pasar yang diproduksi perusahaan luar negeri yang menguasai pasar lokal dengan mengalahkan produk UKM Indonesia. Penyebabnya adalah kemasan produk lokal yang kurang menarik minat lokal dan dianggap tidak higienis. Padahal, apapun produknya, jika dikemas baik maka akan menambah nilai tambah dari produk tersebut. Kemasan produk kita masih sangat 
sederhana untuk bisa bersaing dengan produk luar.

Salah satu faktor penting pada sebuah produk adalah kemasan. Dalam era globalisasi saat ini, kemasan mempunyai peranan yang sangat penting karena akan selalu terkait dengan komoditi yang dikemas dan sekaligus merupakan nilai jual dan citra produk. Nilai jual ini meningkat ketika produk yang dihasilkan mendapat nilai tambah dari kemasan yang menarik. Sedangkan citra produk terkait dengan gambaran produk dalam benak konsumen akan semakin baik apabila produk itu dikemas secara baik, dengan kata lain produk dapat memberi kesan baik bagi konsumen.

Berdasarkan pemaparan diatas, memunculkan gagasan penting adanya sebuah pelatihan terhadap UKM, selain dapat melindungi produk, Packaging juga dapat menambah daya Tarik konsumen.

Pada program ini yang menjadi sasaran pelatihan adalah UKM di Desa Kedaung. UKM tersebut dipilih karena kemasan produk UKM kerap kali dianggap remeh. Program ini mempertimbangkan hal tersebut, mengusulkan penggunaan kemasan dan desain yang baik. Setelah pelatihan ini, diharapkan UKM di kedaung bisa menggunakan kemasan yang menarik minat konsumen dan diharapkan menambah pemasukan UKM.

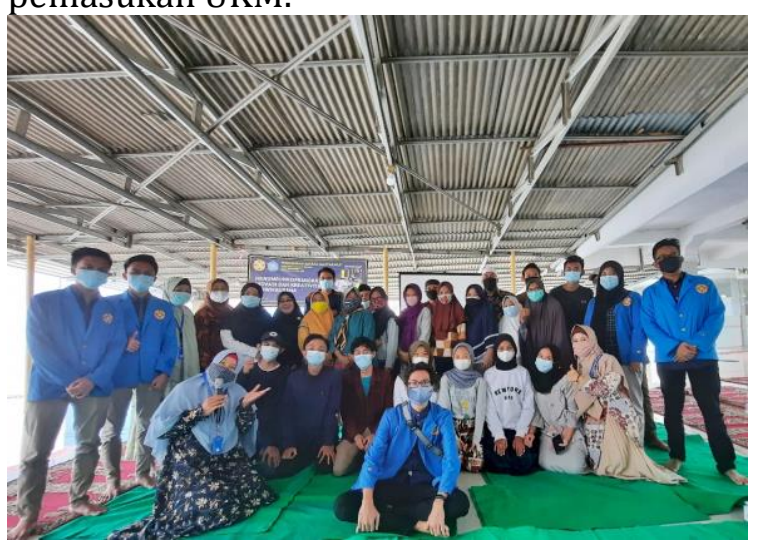

Gambar 1. Foto Bersama

\section{METODE}

Metode kegiatan ini adalah mendatangi tempat di Aula masjid Al-amien, Kedaung dengan memberikan pelatihan serta edukasi mengenai pentingnya desain kemasan dalam produk usaha kepada pelaku usaha dan masyarakat sekitar. Kegiatan ini dilaksanakan oleh Mahasiswa/i dan diperbantukan oleh

\section{HASIL DAN PEMBAHASAN}

Sentuhan akademisi memberi warna dan sudut pandang yang berbeda. Dengan pemaparan dan diskusi serta pelatihan memberi dorongan semangat masyarakat untuk menumbuhkan kesadaran berorganisasi. Masyarakat bukan saja senang didatangi, namun lebih dari itu sebagai sebuah bentuk kegiatan humanis yang sarat akan sentuhan kemanusiaan. Bagi civitas akademika (mahasiswa) khususnya dan bagi masyarakat umumnya. Dengan bersilaturahmi, berdiskusi, berdialog, ramah tamah, membangun relationship menjadi solusi terbangunnya semangat untuk berorganisasi.

\section{PENUTUP}

Kesimpulan yang dapat di ambil dari pelaksanaan Pengabdian Kepada Masyarakat di Kampung Pulo, Kelurahan Desa Kedaung, Tangerang Selatan, yang dilaksanakan pada tanggal 27 Februari 2021 antara lain: Mampu beradaptasi dengan baik, sehingga terjalin hubungan kerjasama dan keberlangsungan acara antara masyarakat dengan mahasiswa. Mahasiswa memberikan edukasi dan pelatihan mengenai bagaimana cara meningkatkan kualitas produk kemasan bagi pelaku UKM dan masyarakat sekitar. Mahasiswa mengadakan sesi tanya jawab dan quiz berhadiah yang bermanfaat bagi masyarakat sekitar Mahasiswa memberikan cinderamata kepada Ketua Koordinator UMKM, Ibu Turipah dan pembagian sertifikat serta kenang-kenangan kepada masyarakat sekitar yang turut serta dalam Pelaksanaan kegiatan PKM ini.

\section{DAFTAR PUSTAKA}

Admin Koperasi. Kriteria Usaha Mikro, Kecil dan Menengah Menurut UU no. 20 Tahun 2008 Tentang UMKM. Diakses di: https://koperasi.kulonprogokab.go.id

Affandi, A., Sarwani, A. S., Erlangga, H., Siagian, A. O., Purwanto, A., Effendy, A. A., ... \& Wahyitno, C. D. M. (2020). Optimization of MSMEs Empowerment in Facing Competition in the Global Market during the COVID-19 Pandemic 
Time. Systematic Reviews in Pharmacy, 11(11), 1506-1515.

Badan Pemeriksa Keuangan Republik Indonesia. Keputusan Presiden RI no. 99 tahun 1998 Pengertian Usaha Kecil Menengah. Diakses di : https://peraturan.bpk.go.id

Erlangga, H. (2021). Effect Of Digital Marketing And Social Media On Purchase Intention of Smes Food Products. Turkish Journal of Computer and Mathematics Education (TURCOMAT), 12(3), 3672-3678.

Haque, M. G., Munawaroh, M., Sunarsi, D., \& Baharuddin, A. (2021). Competitive Advantage in Cost Leadership and Differentiation of SMEs "Bakoel Zee" Marketing Strategy in BSD. PINISI Discretion Review, 4(2), 277-284.

Maharani, P.A. (2018). Analisis Pengaruh Kemasan dan Citra Merek terhadap minat beli konsumen. Skripsi, Universitas Sanata Dharma. Yogyakarta. Diakses di: http://repository.usd.ac.id/30909/2/ 142214111_full.pdf

Nurjaya, N., Erlangga, H., Hong, L. Z., \& Wijayanti, K. D. (2020). The Effect of
Work Stress and Work Conflict on Employees Turnover Intention In Middle Small Micro Enterprises (MSMEs) In South Tangerang Region. International Journal of Educational Administration, Management, and Leadership, 51-62.

Ratriani. (2020). Pengertian dan Kriteria UMKM. Diakses di : https://bit.ly/3vvuwVC Pada 27 Februari 2021

Safitri, R. (2018). Faktor-Faktor Yang Mempengaruhi Penggunaan Informasi Akuntansi Pada Usaha Kecil Menengah Di Kecamatan Bungkal Kabupaten Ponorogo. Skripsi (S1) thesis, Universitas Muhammadiyah Ponorogo.

Diakses di: http://eprints.umpo.ac.id/3971/3/3. \%20BAB\%20II.pdf

Wardani, K.H. (2013). Peranan Dinas Koperasi dan UKM Dalam Pemberdayaan Usaha Kecil Menengah Kota Malang. Jurnal Administrasi Publik (JAP), Vol 1, No.2, hal. 213-220. Diakses di: http://studentjournal.ub.ac.id 